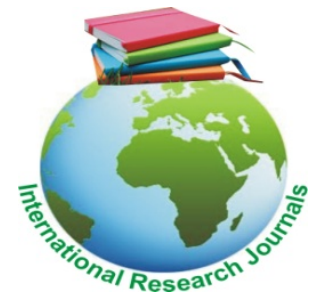

\title{
Ocular findings in muscular dystrophies
}

\author{
Ferhat Evliyaoglu ${ }^{1}$, Ahmet Z. Burakgazi ${ }^{2 *}$ \\ ${ }^{1}$ Mus State Hospital, Mus, Turkey \\ ${ }^{2}$ Section of Neuroscience, Department of Medicine, Virginia Tech Carilion School of Medicine, Roanoke, VA, USA \\ ${ }^{*}$ Correspondence Author's Email: drburakgazi@yahoo.com
}

\begin{abstract}
Muscular dystrophies are a heterogeneous class of inherited disorders presenting with different clinical, genetic, and biochemical features. Muscular dystrophies include Duchennemuscular dystrophy (DMD) and Becker muscular dystrophy (BMD) myotonic dystrophy (DM), oculopharyngeal muscular dystrophy (OPMD), facioscapulohumeral muscular dystrophy (FSHD), limb-girdle muscular dystrophy (LGMD), distal muscular dystrophy, and congenital muscular dystrophy (CMD)types, each with a wide spectrum of clinical manifestations. Those muscular dystrophies can have similar symptoms or unique and specific presentations. This abstract will review the prevalence, clinical presentation, and management of ocular findings in certain muscular dystrophies.

Keywords: Muscular dystrophies, Ocular findings, Duchenne and Becker muscular dystrophies, myotonic dystrophies, oculopharyngeal muscular dystrophy, facioscapulohumeral muscular dystrophy, limb-girdle muscular dystrophy, distal muscular dystrophy, and congenital muscular dystrophy
\end{abstract}

\section{ABBREVIATIONS}

AD: Autosomal dominant

ANO5: Anoctamins 5

AR: Autosomal recessive

DMD: Duchennemuscular dystrophy

BMD: Becker muscular dystrophy

CMD: Congenital muscular dystrophy

MDC1C: Congenital muscular dystrophy $1 \mathrm{C}$

MDC1D: Congenital muscular dystrophy 1D

CPEO: Chronic progressive external ophthalmoplegia

DM: Myotonic dystrophy

EOM: Extraocular muscles

FSHD: Facioscapulohumeral muscular dystrophy

FCMD: Fukuyama congenital muscular dystrophy

GDP: Guanosinediphosphate

GMPPB: Guanosinediphosphate mannose pyrophosphorylase B

LGMD: Limb-girdle muscular dystrophy; MEB: Muscle eye brain disease

OPMD: Oculopharyngeal muscular dystrophy

POMGNT1: ProteinO-linked-mannosebeta-1,2-N-acetylglucosaminyl transferase 1

SP: Smooth pursuit

VOR-S: Vestibulo-ocular reflex suppression

WWS: Walker-Warburg syndrome

\section{INTRODUCTION}

Muscular dystrophies are a heterogeneous class of inherited disorders presenting with different clinical, genetic, and biochemical features (Mercuri and Muntoni, 2013,Miller 1985). They are characterized by progressive 
weakness in facial, limb, and axial muscle groups to a variable degree. Involvement of other organ systems such as the brain, inner ear, eyes, or skin can be rarely seen in muscular dystrophies. (Mercuri and Muntoni, 2013), (Anastasopoulos et al.1996). In this article, we focus on the prevalence, clinical presentation, and management of ocular findings in certain muscular dystrophies including DMD and BMD, DM, OPMD, FSHD, LGMD, distal muscular dystrophy, and CMD.

\section{Duchenne and Becker Muscular Dystrophies}

DMD is the most frequently seen, most severe form of muscular dystrophy. (Mercuri and Muntoni, 2013) DMD has an unremitting and progressive course, and mainly affects males. (Bellayou et al. 2009) Bellayou et al. 2009) $B M D$ is a less severe formof the disease and has a slower progression. Bellayou et al. 2009, Aartsma-Rus et al.2006, Chakkalakal et al. 2005).DMD and BMD are Xlinked muscular dystrophies. The incidence of DMD is around1 in 3,500 male births (2.9 per 10,000 males), whereas the incidence of BMDisaround1 in 18,518 male births (0.5 per 10,000 males). (Emery 1991) The prevalence of DMD is approximately 1.3 to 1.8 per 10,000 males aged 5 through 24 years (Miller et al. 2006).

Dystrophin is an essential protein for the frame of skeletal muscles and a part of dystrophin-associated glycoprotein complex (Ervasti and Campbell, 1991), which is responsible fora critical connection between the cytoskeleton and extra-cellular matrix. Its absence or abnormality can cause myofiber necrosis, progressive muscle weakness, and fatigability. D (Porter and Baker, 1996) MD is caused by a defect in the dystrophin gene, leading to a lack of dystrophin protein in the affected individuals. In BMD, an abnormal version of dystrophin retains some function of the muscle tissues. (Blake et al. 2002) Patients with DMD typically become wheelchair dependent before the age of twenty. Death usually occurs by age thirty due to cardio respiratory complications. (Kaminski et al.1992).

Interestingly, extraocular muscles (EOM) are a few skeletal muscle groups that retaina normal structure and function in both DMD and BMD. (Ervasti and Campbell, 1991) EOM's ability to retain a normal structure and function in patients diagnosed with DMD and BMDmay depend on EOM'sindistinct features whichprotect it fromthe toxic effects of intracellular calcium, which is related to myofibril necrosis in absence of dystrophin (Khurana et al. 1995). In addition, saccadic eye movements in DMD patients are similar when comparedto individuals who have not been diagnosed with DMD (Khurana et al. 1995).

The histopathologic analysis of EOM in patients with DMD revealsEOMshave high mitochondrial contents and their configurations are different from other skeletal muscles that provide unique contraction speed and fatigue resistance in EOMs (Porter and Baker, 1996). Myosin heavy chain composition and distribution is different in EOMs thanin limb muscles. Furthermore, EOM has a slower course of development in the embyrogenic stage than limb muscles (Pedrosa-Domellof et al. 2000).

In Porter et al.'s study investigating EOM function of mdx mice (commercially available dystrophin-deficient mice), it was demonstrated that the level of utrophin protein was higher in the EOMs of mdx mice and there was no specific muscle fiber alteration in EOMs when compared to limb muscles in $\mathrm{mdx}$ mice. It was postulated that elevated utrophin levels might mediate the rescue of eye muscle in DMD/BMD (Porter et al. 1998). Although impairment of EOM in DMD/BMD was shown by oculography in some studies, it is not supported by randomized double blind clinical trials (Scelsa et al. 1996, Lui et al. 2001).

\section{Myotonic Dystrophy}

DM is an autosomal dominant, multisystem disorder and occurs as a result of an unstable triplet expansion of nucleotides on certain areas of DNA (Brook et al. 1992). Progressive expansion of the triple insertion with succeeding generations can cause generic anticipation. The clinical manifestations of the MD include muscle wasting, weakness, myotonia (delayed muscle relaxation following contraction), abnormal cardiac conduction, mental retardation, testicular atrophy, hyperinsulinemia, and frontal baldness. The ocular manifestations mainly include ptosis and cataract, blepharitis and in rare cases, diplopia or restriction of the range of eye movements (Miller et al. 2006). Almost one-third ofpatients have lower than normal intraocular pressure, presumably resulting from decreased aqueous production. (Walker et al. 1982) The cataract in MD often contains iridescent deposits within a thin band of the anterior and posterior cortex. The red, blue, green, and white flecks are visible on slit lamp examination and their distribution in the lens cortex is thought to be highly specific toMD. Those flecks can distinguish from the more common iridescent refractile flecks in age-related cataracts. (Miller et al. 2006) Varieties of pupillary abnormalities have been described in MD, but most patients have normal pupillary response to light. Pigmentary changes in the macula resemble those of pattern dystrophy, but are not a common cause of vision reduction. ${ }^{20}$ Peripheral retinal pigment epithelial atrophy and clumping has been described and probably causes few, if any, clinical symptoms (Raitta and Karli, 1982, Betten et al. 1971).

Besides these ocular findings, the slowing of saccades and attenuation of smooth pursuit gain have been demonstrated in MD patients by means of oculographic recordings. (Baloh et al. 1975) The decrease in saccadic eye movements is a subclinical feature of the disease 
noted in the literature, but its pathophysiologicmechanism has remained controversial. It has been postulated that the decrease in saccadic eye movementsstems from dystrophic changes in the extraocular muscles. (Oohira rt al. 1983, Burian and Burns, 1966). The histopathologic assessment of extraocular muscles reveals dystrophic changes as well. (Davidson 1961, Kuwabara and Lessell, 1976). The finding of a 'warming-up' phenomenon for repetitive saccades is explained in terms of myotonia, (Hansen et al. 1993) which is known to involve the extraocular eye muscles (Oohira rt al. 1983, Burian and Burns, 1966). In other traditions, it is hypothesized that the phenomena may be sourced from a central origin. (Emre 1985) Anastasopoulos et al. postulatedthat a central or peripheral origin causes oculomotor abnormalities in patients with MD. They studied both slow and fast eye movements and compared smooth pursuit (SP) performance with theability to suppress the vestibule-ocular reflex by visual fixation (vestibulo-ocular reflex suppression (VOR-S). It was concluded that the parallel degradation of SP and VOR-S in MD patients might reflect a central deficit (Anastasopoulos et al. 1996).

\section{Oculopharyngeal muscular dystrophy}

In 1962, Victor and colleagues described a neuromuscular disease manifesting with unique relation of progressive externalophthalmoplegia and pharyngeal weakness that was subsequently namedOPMD. (Victor et al. 1962) OPMD was first described by Taylor (Taylor 1915) as a progressive cranial neuropathy. OPMD is caused by a mutation in the PABN1 gene, which is encoded by the long arm of chromosome 14. (Brais 2003) Selective involvement of ocular and pharyngeal muscle may depend on a continued remodeling process in these muscle groups, which make them vulnerable to the effects of the disease. (Wirtschafter et al. 2004) Although it is clear that the disease is inherited in an autosomal dominant (AD) fashion, a few cases of autosomal recessive (AR) type OPMD have been reported. (Brais et al.1998) The disease has a regional disturbance and runsamong families. In the late 1960sin Quebec, Canada, the estimated prevalence of OPMD was 1:1000. (Francois 1969) Its prevalence is around1:600 among the Bukhara Jewish population. (Blumen et al. 1997) A study analyzing 216 cases of OPMD in Hispanic populations in New Mexico, USAdemonstrates that OPMD is not limited to the French-Canadian population in Quebec and is seen in Hispanic populations as well (Becher et al. 2001).

OPMDrelated symptomsusually become prominent around age forty and all patients become symptomatic before the age of 70 . In addition to ptosis and dysphagia, the affected individuals may suffer from tongue atrophy and weakness, proximal lower extremity weakness, dysphonia, limitation of upward gaze, facial muscle weakness, and proximal upper extremity weakness. (Bouchard et al. 1997) Levator palpebral muscle weakness can cause ptosis in OPMD. The first symptom is usually ptosis in OPMD, followed by dysphagia. Ptosis is always bilateral in OOPMD.Affected individuals contract frontal muscles and recline their head to compensate for disrupted visual fields, so a typical posture occurs, which is called "asstrologist" posture. (Ruegg et al. 2005) Although the astrologist posture is notcommonly used in clinical practice, it may be an important feature of the disease and may differentiate it from chronic progressive external ophthalmoplegia (CPEO), which is also characterized by bilateral ptosis besides ophthalmoplegia. (Smits et al. 2011) Eyelid drooling is the most bothering finding in CPEO patients; fortunately reconstructive surgery usually provides satisfactory results (Rodrigue and Molgat, 1997).

EOM can be involved in OPMD and may result in ophthalmoplegia and strabismus. Hill and colleagues analyzed 31 OPMD patients in the United Kingdom and reported that half of the patientsthere had some limitation of EOM, which were graded moderate or severe and described as ophthalmoplegia. (Hill et al. 2001) Although ophthalmoplegia is a common sign of the disease, the (Salvesen and Brautaset, 1996) affected individuals usually have a slight degree of ophthalmoplegia (Salvesen and Brautaset, 1996), which becomes prominent during examination. Full range of external ophthalmoplegia is rare and intrinsic eye muscles (cilliary and sphincter muscles of the iris) are not involved in OPMD. (Tomé 1994) Since the degree of ophthalmoplegia is slight, diplopia is not a common sign and may become more prominent in forced movements of the eye.

\section{Facioscapulohumeral muscular dystrophy}

FSHD is one of the most common types of muscular dystrophy, first described in 1884 by Landouzy and Dejerine. It is characterized bymuscle weakness and atrophy, especially in the upper part of the body. Estimated incidence of the disease is 1 in 15,000 to 20,000 dependingon the population sampled. (44) FSHD can be classified into two different types based on genetic defects. In FSHD type 1 (95\%)there is a deletion in the units of D4Z4 DNA repeat sequence, which is located on the subtelomeric region of the long arm of chromosome 4 (4q35). (Lee et al. 1995) A small amount of FSHD cases (less than $5 \%$ ) are called FSHD type 2, resulting from a methylation defect in D4Z4 when compared to the deletion in type 1 (de Greef et al. 2009).

FSHD is a genetic disorder and inherited with $A D$ fashion. Although it can occasionally be seen in sporadic form, $90 \%$ of affected individuals carry the $A D$ gene. General signs and symptoms of the disease become 
apparent during early adolescence, but onset and severity of the disease can show extreme variability even in the same family. Although a vast majority of casespresent during adolescence, rare forms of severe FSHD can present during early childhood, with some mild forms of FSHD becomingapparent by or around age forty.

Muscle weakness and atrophy are first seen in facial muscles and one side of the face is usually affectedmore severelythan the other side. Affected individuals have difficulty closing their eyes and smiling, which results in a transverse smile. Whistling and drinking is difficult due to weakness of muscles around the mouth as well. Shoulder weakness is another common symptom of the disease, presenting with winging scapuladue to weakness ofthe surrounding muscles. Bilateral tibialis anterior involvement is highly characteristic of the disease, resulting in gait disturbance. Muscle pain is also reported in FSHD and can be seen as a prominent symptom of the disease. (Bushby et al. 1998) Pain is usually located around the joints where affected muscles are located. (Bushby et al. 1998).

Although extra-ocular muscle involvement is extremely rare in FSHD and sparing of extra-ocular muscle involvement is accepted as one of the diagnostic criteria of FSHD (Padberg et al. 1991), three FSHD patients with progressive external ophthalmoplegia have been reported in literature. (Krasnianski et al. 2003).

Eyelid weakness is seen in FSHD and FSHD patients may not be able to close their eyelids tightly, leading to lagophthalmos. Exposure keratopathy is a potential complication of this situation if appropriate treatment is not given. Besides medical treatment, surgical intervention may be considered in severe situation with gold implants in the eyelid (Sansone et al. 1997).

FSHD patients frequently suffer from Coats' disease of the eye, which is characterized by telengectasic vessels in the peripheral retina (Small 1968, Statland et al. 2013). It was first described by Small (Small 1968) in four siblings with exudative telangiectasia of the retina and FSHD in 1968. Fitzsimons et al. performed detailed examinations including fundus angiography inthe eyes of 75 FSHD patients and demonstrated peripheral retinal capillary abnormalities including telangiectasia, leakage and micro aneurysm formation (Fitzsimons et al. 1987). (Padberg et al. 1995) also demonstrated retinal vasculopathy in $49 \%$ of patients with FSHD by using retinal angiography. (Padberg et al. 1995)Two exudative retinal detachments due to retinal telangiectasia in FSHD were reported in the literature. (Pauleikhoff et al. 1992) Since retinal detachment is a severe complication of Coats' disease, clinicians should carefully perform eye examination in patients with FSHD to prevent a potential visual loss with laser treatment applied to theinvolved areas of the retina. Previous studies demonstrated a clear relationship between Coats 'disease and FSHD. However, a recent survey study reported that Coats' disease was a rare complication of FSHD-1 in patients with a large deletion of D4Z4. A survey of 357 patients with FSHD-1 conducted a found that only 14 had Coats disease. This study suggests a need for closer surveillance for retinal complications in patients with small amounts of D4Z4 fragments $(\leq 15 \mathrm{~kb})$ (Statland et al. 2013).

\section{Limb-girdle muscular dystrophy}

LGMD is a heterogenic group of diseases that usually involvethe shoulder and the hip girdle muscles,sparing the facial muscles. (van der Kooi et al. 1996) LGMD is sub-classified into two main categories according to their inheritance. LGMD type 1 is inherited as AD fashion while LGMD type 2 is inherited in ARform. (Van der Kooi et al. 1996, Urtasun et al. 1998). The AR form is more common and accounts for almost $90 \%$ of the presented type of the disease. Although it is difficult to estimate prevalence of LGMD due to its many subtypes; it is estimated at $1: 14,500$ to $1: 123,000$ for all subtypes. (van der Kooi et al. 1996,Urtasun et al. 1998).

Facial muscles are almost exclusively spared in LGMD. LGMD1C is a subtype of LGMD that is caused by a mutation in the caveolin 3 gene, which is responsible for producing a protein called caveolin 3 that has an important role in the formation of muscle fibers (Minetti et al. 1998). although it presents with proximal muscle weakness like other types of LGMD, ophthalmoplegia, exophthalmos and blepharoptosis have been reported in LGMD1C (Filosto et al. 2009). Guanosinediphosphate mannose (GDP-mannose) pyrophosphorylase B.

(GMPPB ) is an enzyme that catalyzes the formation of GDP-mannose from guanosine triphosphate and mannose-1-phosphate that is required in glycosylation pathways (Carss et al. 2013). A defect in the GMPPB gene specifically may cause brain and eye problems (Carss et al. 2013). In a study investigating eight cases with a GMPPB gene defect, LGMD and congenital muscular dystrophy were diagnosed in some of the cases.LGMD with GMPPB gene defect manifests with mental retardation, microcephaly, epilepsy, and ocular findings including childhood cataract formation, ptosis, strabismus, nystagmus and retinal diseases (Carss et al. 2013).

Anoctamins are related to calcium activated chloride channels and consist of 10 members (Hartzell et al. 2009). A recessive mutation in anoctamins 5 (ANO5) results in a subtype of LGMD, which is coded as LGMD2L (6). A case study with macular dystrophy was reported in one of two siblings with LGMD2L with ANO5 mutation (Vaz-Pereira et al. 2014). Although the association is not clearly demonstrated, it may be due to a dysfunction in calcium activated chloride channel in retinal pigment epithelium (Vaz-Pereira et al. 2014).

POMGNT1 (Protein O - linked - mannosebeta -1,2-Nacetyl glucosaminyltransferase 1 ) is an enzyme encoded 
by the POMGNT1 gene. The product of the POMGNT1 gene participates in synthesis of O-mannosylglycan (Akasaka-Manya et al. 2011). A mutation in the POMGNT1 can cause Muscle eye brain disease (MEB) and LGMD2O, which is a rare subtype of LGMD. Although POMGNT1 mutation may be associated with congenital glaucoma, retinal dysplasia, and high rates of myopia in literature, reported cases of LGMD2O did not have eye problems except one case, where the patient presented with severe myopia (Clement et al. 2008, Raducu et al. 2012).

LGMD is a progressive disease and no specific treatment is available for any subtypes of LGMD. The primary aim in LGMDis to prevent complications of the disease and improve the patient's quality of life. Physical therapy and occupational therapy have a major role in treatment of LGMD. In a novel study, it is reported that chronic oral administrationof angiotensin 1-7 (Ag1-7) may improve skeletal muscle function in patients with LGMD2F (Sabharwal et al. 2014). Gene therapy also has promising results in patients with LGMD2D, which is used adenovirus associated vector and showed six months of sustained $\alpha$-sarcoglycan gene expression in 2 of 3 patients' that were defected in LGMD2D subtype (Mendell et al. 2010).

\section{Distal muscular dystrophy}

Distal muscular dystrophies (distal myopathy) are a group of inherited muscular diseases primarily affecting the hands and feet (Lu et al. 2008). Distal muscular dystrophy is a common name.Almost 20 different entities of distal muscular dystrophies have been genetically determined, but well-known types include Welander, Finnish (tibial), Miyoshi, Nonaka, Gowers-Laing, hereditary inclusion-body myositis type 1 , distal myopathy with vocal cord and pharyngeal weakness, and ZASPrelated myopathy (Lu et al. 2008, Udd 2009). Clinical presentation and inheritance pattern of these myopathies are not uniform. In literature, there are some rare types of distal muscular dystrophies but the classificationsare difficult to make because some subtypes are not well documented and retrospective analysis has not been performed properly (Udd 2009, Pitceathly et al. 2013).

Distal muscular dystrophies generally present with progressive weakness in the legs, hands and feet. Mutated genes are responsible from sarcomeric protein production that causes the disease. Affected individuals usually have normal or slightly increased levels of creating kinase. Ocular involvement is not typically seen in distal muscular dystrophy. In literature there area few, very rare cases presenting with ocular muscle involvement in distal muscular dystrophy. Two patients with upper limb predominant distal myopathy presented with progressive external ophthalmoplegia and had cataract operation in early life (Pitceathly et al. 2013).
Further investigation showed novel pathogenic heterozygous POLG missense mutations causing $\mathrm{mt}$ DNA depletion and representing itself in upper limb predominant distal myopathy with ocular involvement (Pitceathly et al. 2013). Distal myopathy and progressive external ophthalmoplegia were reported in the same patient but a type of distal myoptahy was not reported in this case (Damian 1993). Oculopharyngodistal myopathy is a rare clinical entity and is accepted as a distal myopathy. It is characterized byptosis, external ophthalmoplegia, dysphagia, and distal weakness. Although oculopharyngodistal myopathy has a similar presentation toOPMD, genetic features are different between the two diseases (Minami et al. 2001). In a study, oculopharyngodistal myopathy was reported in 47 patients from 9 unrelated Turkish families (Durmus et al. 2011). The common initial symptom was ptosis, followed by oropharyngeal symptoms and distal muscular weakness (Durmus et al. 2011). Both AD and AR traits were reported, but no clinical differences were found between $A D$ and $A R$ types (Durmus et al. 2011). The AR form of the disease is rare and was previously reported in two Japanese brothers and two Dutch siblings (Uyama et al. 1998, van der Sluijs et al. 2004). It is shown that a patient with the AR form of the disease has more severe presentation and earlieronset of the disease in comparison to the AD form (van der Sluijs et al. 2004).

Furthermore, external ophthalmoplegia, dysphagia, distal weakness and atrophy in all extremities have been reported in Chinesefamilies. That clinical entity was also accepted as oculopharyngodistal myopathy. The histopathologic examination of a muscle biopsy revealed numerous tubulofilamentous inclusions in both the sarcoplasm and nucleus (Lu et al. 2008). Each type of distal muscular dystrophy has its own presentation so management of the disease changes according to the clinical concern. Occupational therapy, physiotherapy and some types of braces may be effective when there isdistal muscular involvement, while surgical therapy may be requiredforocular involvement, especially in cases where there is severe blepharoptosis and facial palsy (Shimizu et al. 2013).

\section{Congenital muscular dystrophy}

CMD is clinically and genetically a heteregenous group of diseases in which affected individuals have its related symptoms atbirth. It has a progressive nature and affected individuals may improve, worsen, or stabilize duringthe acute period of the disease.Due to general worsening of muscle weakness over time, some kind of joint deformities and contractures, such as spinal deformities, can be seen. It is difficult to estimate the prevalence of CMD due to a lack of exact diagnosis with genetic confirmation but it is reported as ranging from 0.68 to 2.5 per 100,000 in a few studies (Darin 2000, Norwood et al. 2009). 
Hypotonia may be noted in utero and in birth. Further developmental delays can be seen over time. Joint and spinal deformities are prominent features of CMD. Although arrest or delay in motor abilities is marked in many individuals, it can be difficult to estimate the onset of disease but the diagnosis is usually made before two years of age. Muscle weakness is a prominent feature of CMD but the affected individualsmayhave some serious complications such as feeding difficulty and respiratory failure. Furthermore, central nervous system, heart and eye involvements can be seen in some subtypes (Sparks et al. 1993).

CMD can be divided into four main groups according to the affected type of proteins: structural proteins, glycosylation proteins, endoplasmic reticulum proteins, and nuclear envelope proteins. The four main groups can be further divided into many subtypes by involved gene, which may cause variability in phenotypes. Eye abnormalities are almost exclusively specific for dystroglycanopathy, which is caused by a defect in glycosylation (Sparks et al. 1993). There are five wellknown types of dystroglycanopathy:

\section{a) Fukuyama congenital muscular dystrophy (FCMD)}

FCMD is an AR form of CMD and characterized by generalized muscle weakness, severe brain involvement with impaired cognitive function, seizure and abnormal eye function (Muntoni and Voit 2004). In affected individuals, both anterior and posterior segments of the eye can be affected in addition to ocular muscle involvement. Eye involvement can be seen in $50 \%$ of the affected individuals. Abnormal eye movements, strabismus, poor visual pursuits, myopia, hyperopia, and cataract have been reported in FCMD. Retinal detachment and microphthalmos can be seen in some rare cases (Muntoni and Voit 2004, Yoshioka et al. 1992).

\section{b) Muscle eye brain disease (MEB)}

MEB has a similar presentation with FCMD and was first described by (Santavuori et al. 1989). It is characterized by congenital muscular dystrophy, brain malformation, mental retardation, and ocular abnormalities. Hydrocephalus, lisencephaly, abnormal electroencephalograms and myoclonic jerks are marked central nervous system features of MEB. Severe congenital myopia, congenital glaucoma, pallor of the optic discs, retinal hypoplasia, retinal detachment, nystagmus, enophtalmus, microphthalmia, optic atrophy, juvenile cataracts, and uncontrolled eye movements are associated ocular findings of MEB (Demir et al. 2009, Pihko et al. 1995). The flash VEPs were exceptionally high in MEB, which helps to differentiate it from FCMD (Santavuori et al. 1989).

\section{c) Walker-Warburg syndrome (WWS)}

WWS (also known as cerebroocular dysplasia-muscular dystrophy) is the most severe form of dystroglycanopathy. Itwas first described by Walker in 1942 andthe full clinical picture was delineated by Warburg in 1982.The life expectancy for individuals affected with WWSis less than 3 years (Walker 1942, Cormand et al. 2001). WWS is caused by a mutation in POMT1, which also causes limb-girdle muscular dystrophy-dystroglycanopathy type C1 (Longman et al. 2003). WWSis also associated with type II cobblestone lissencephaly, hydrocephalus, cerebellar malformations and eye abnormalities. The major ocular abnormalities are buphthalmos, congenital glaucoma, microphthalmia, cataract, immature anterior chamber angle, retinal dysplasia with or without retinal detachment, persistent hyperplastic primary vitreous, optic nerve hypoplasia, and coloboma. (Cormand et al. 2001, Brasseur-Daudruy et al. 2012).

d) Congenital muscular dystrophy 1C (MDC1C) : MDC1Cis a rare type of CMD that is inherited as AR form and caused by a defect in the fukutin related protein gene, which is also defected in LGMD type 2l (Brown et al. 2004). MDC1C is associated with hypotonia, feeding difficulties and severe weakness (Brockington et al. 2001). Although facial weakness is associated with MDC1C, ocular involvement is not a prominent feature of the disease. The reported ocular findings are strabismus and ophthalmoplegia in MDC1C (Louhichi et al. 2004).

e) Congenital muscular dystrophy type 1D (MDC1D) :MDC1D is a novel type of dystroglycanopathy in which the affected gene is called LARGE (like glycosyltransferase) (Longman et al. 2003). Horizontal nystagmus, mild myopia and strabismus have been reported in MDC1D in addition to central nervous system and retinal involvements (Longman et al. 2003, Clarke et al. 2011).

\section{CONCLUSION}

Muscular dystrophies are a heterogeneous group of inherited disorders. Those muscular dystrophies can have similar symptoms and can have unique and specific presentations. We summarize ocular findings in certain muscular dystrophies. For instance, extraocular muscles are a few skeletal muscle groups that have a normal structure and function in DMD and BMD. No specific ocular findings have been reported in DMD and BMD. The primary ocular manifestations of DM are ptosis and cataract, blepharitis and, rarely, diplopia or restriction of the range of eye movements. The first symptom is 
usually ptosis in OPDM, followed by dysphagia. Ptosis is always bilateral in OPDM. EOM can be involved in OPMD and may result inophthalmoplegia and strabismus. EOM involvement is extremely rare and sparing of extra-ocular muscle involvement is accepted as one of the diagnostic criteria of FSHD. FSHD patients frequently suffer from Coats' disease of the eye, which is characterized by telengectasic vessels in the peripheral retina. LGMD usually presents with proximal muscle weakness, but ophthalmoplegia, exophthalmos and blepharoptosis have been reported in certain types of LGMB such as LGMD1C and LGMD2L. Ocular involvement is not typically seen in distal muscular dystrophy. In literature there are very rare cases presenting with ocular muscle involvement in distal muscular dystrophy. Eye abnormalities are almost exclusively specific to dystroglycanopathy in CMD. Clinical treatments arelimited and surgical corrections can be performed in selected cases.

\section{REFERENCES}

Aartsma-Rus A, Kaman WE, Weij R, den Dunnen JT, van Ommen GJ, van Deutekom JC (2006). Exploring the frontiers of therapeutic exon skipping for Duchenne muscular dystrophy by double targeting within one or multiple exons. Mol Ther; 14: 401-7.

Akasaka-Manya K, Manya H, Mizuno M, Inazu T, Endo T (2011). Effects of length and amino acid sequence of O-mannosyl peptides on substrate specificity of protein O-linked mannose beta1,2-Nacetylglucosaminyltransferase 1 (POMGnT1). Biochem Biophys Res Commun; 410: 632-6.

Anastasopoulos D, Kimmig H, Mergner T, Psilas K (1996). Abnormalities of ocular motility in myotonic dystrophy. Brain; 119: 1923-32.

Baloh RW, Konrad HR, Sills AW, Honrubia V (1975). The saccade velocity test. Neurology; 25: 1071-6.

Becher MW, Morrison L, Davis LE, Maki WC, King MK, Bicknell JM (2001). Oculopharyngeal muscular dystrophy in Hispanic New Mexicans. JAMA; 286: 2437-40.

Bellayou H, Hamzi K, Rafai MA, Karkouri M, Slassi I, Azeddoug H, Nadifi SI (2009). Duchenne and Becker muscular dystrophy: contribution of a molecular and immune histo chemical analysis in diagnosis in Morocco. J Biomed Biotechnol; 2009: 325210.

Betten MG, Bilchik RC, Smith ME (1971). Pigmentary retinopathy of myotonic dystrophy.Am J Ophthalmol; 72: 720-3.

Blake DJ, Weir A, Newey SE, Davies KE (2002). Function and genetics of dystrophin and dystrophin-related proteins in muscle. Physiol Rev; 82: 291-329.

Blumen SC, Nisipeanu P, Sadeh M, Asherov A, Blumen N, Wirguin Y (1997). Epidemiology and inheritance of oculopharyngeal muscular dystrophy in Israel. Neuromuscul Disord; 7 Suppl 1: S38-40.

Bouchard JP, Brais B, Brunet D, Gould PV, Rouleau GA (1997). Recent studies on oculopharyngeal muscular dystrophy in Quebec. Neuromuscul Disord; 7 Suppl 1: S22-9.

Brais B (2003). Oculopharyngeal muscular dystrophy: a late-onset polyalanine disease. Cytogenet Genome Res; 100: 252-60.

Brais B, Bouchard JP, Xie YG, Rochefort DL, Chrétien N, Tomé FM (1998). Short GCG expansions in the PABP2 gene cause oculopharyngeal muscular dystrophy. Nat Genet; 18: 164-7.

Brasseur-Daudruy $M$, Vivier $P H$, Ickowicz $V$, Eurin $D$, Verspyck $E$ (2012). Walker-Warburg syndrome diagnosed by findings of typical ocular abnormalities on prenatal ultrasound. Pediatr Radiol; 42: 48890.

Brockington M, Yuva Y, Prandini P, Brown SC, Torelli S, Benson MA (2001). Mutations in the fukutin-related protein gene (FKRP) identify limb girdle muscular dystrophy $2 \mathrm{I}$ as a milder allelic variant of congenital muscular dystrophy MDC1C. Hum Mol Genet; 10: 2851-9.

Brook JD, McCurrach ME, Harley HG, Buckler AJ, Church D, Aburatani $H$ (1992). Molecular basis of myotonic dystrophy: expansion of a trinucleotide (CTG) repeat at the $3^{\prime}$ end of a transcript encoding a protein kinase family member. Cell; 68: 799-808.

Walker SD, Brubaker RF, Nagataki S (1982). Hypotony and aqueous humor dynamics in myotonic dystrophy. Invest Ophthalmol Vis Sci; 22: 744-51.

Brown SC, Torelli S, Brockington M, Yuva Y, Jimenez C, Feng L (2004). Abnormalities in alpha-dystroglycan expression in MDC1C and LGMD2I muscular dystrophies. Am J Pathol; 164: 727-37.

Burian HM, Burns CA (1966). Ocular changes in myotonic dystrophy. Trans Am Ophthalmol Soc; 64: 250-73.

Bushby KM, Pollitt C, Johnson MA, Rogers MT, Chinnery PF (1998). Muscle pain as a prominent feature of facioscapulohumeral muscular dystrophy (FSHD): four illustrative case reports. Neuromuscul Disord; 8: 574-9.

Carss KJ, Stevens E, Foley AR,, Cirak S, Riemersma M, Torelli S (2013). Mutations in GDP-mannose pyrophosphorylase B cause congenital and limb-girdle muscular dystrophies associated with hypoglycosylation of alpha-dystroglycan. Am J Hum Genet; 93: 2941.

Chakkalakal JV, Thompson J, Parks RJ, Jasmin BJ (2005). Molecular, cellular, and pharmacological therapies for Duchenne/Becker muscular dystrophies. FASEB J; 19: 880-91.

Clarke NF, Maugenre S, Vandebrouck A, Urtizberea JA, Willer T, Peat RA (2011).Congenital muscular dystrophy type 1D (MDC1D) due to a large intragenic insertion/deletion, involving intron 10 of the LARGE gene. Eur J Hum Genet; 19: 452-7.

Clement EM, Godfrey C, Tan J, Brockington M, Torelli S, Feng (2008). Mild POMGnT1 mutations underlie a novel limb-girdle muscular dystrophy variant. Arch Neurol; 65: 137-41.

Cormand B, Pihko H, Bayes M, Valanne L, Santavuori P, Talim B (2001). Clinical and genetic distinction between Walker-Warburg syndrome and muscle-eye-brain disease. Neurology; 56: 1059-69.

Damian C (1993). Progressive external ophthalmoplegia and distal myopathy. Oftalmologia; 37: 65-7.

Darin N, Tulinius M (2000). Neuromuscular disorders in childhood: a descriptive epidemiological study from western Sweden. Neuromuscul Disord; 10: 1-9.

Davidson SI (1961). The Eye in Dystrophia Myotonica: With a Report on Electromyography of the Extra-Ocular Muscles. $\mathrm{Br} \mathrm{J}$ Ophthalmol; 45: 183-96.

de Greef JC, Lemmers RJ, van Engelen BG (2009). Common epigenetic changes of D4Z4 in contraction-dependent and contraction-independent FSHD. Hum Mutat 30: 1449-59.

Demir E, Gucuyener K, Akturk A, Talim B, Konus O, Del Bo R (2009). An unusual presentation of muscle-eye-brain disease: severe eye abnormalities with mild muscle and brain involvement. Neuromuscul Disord; 19: 692-5.

Durmus H, Laval SH, Deymeer F, Parman Y, Kiyan E, Gokyigit M (2011). Oculopharyngodistal myopathy is a distinct entity: clinical and genetic features of 47 patients. Neurology; 76: 227-35.

Emery AE (1991). Population frequencies of inherited neuromuscular diseases--a world survey. Neuromuscul Disord; 1: 19-29.

Emre MHV (1985). Central eye movement disorder in a case of myotonic dystrophy. Neuro-ophthalmology; 5: 21-5.

Ervasti JM, Campbell KP (1991). Membrane organization of the dystrophin-glycoprotein complex. Cell; 66: 1121-31.

Filosto M, Tonin P, Vattemi G,Scarpelli M, Baronchelli C, Broglio L (2009). Chronic ophthalmoparesis in limb girdle muscular dystrophy 1C. J Neurol Neurosurg Psychiatry; 80: 448-9.

Fitzsimons RB, Gurwin EB, Bird AC (1987). Retinal vascular abnormalities in facioscapulohumeral muscular dystrophy. A general association with genetic and therapeutic implications. Brain; 110: 631-48.

Francois J (1969). Congenital ophthalmoplegias. In: Brunette J-R, Barbeau A (eds): Progress in Neuro-Ophthalmology, vol. 2. Amsterdam, Excerpta Medica,

Hansen HCLC, Crawford TJ, Kennard C, Zangemeister WH (1993). Evidence for the occurrence of myotonia in the extraocular 
musculature in patients with dystrophia myotonica Neuroophthalmology; 13: 17-24.

Hartzell HC, Yu K, Xiao Q, Chien LT, Qu Z (2009). Anoctamin/TMEM16 family members are Ca2+-activated $\mathrm{Cl}$ - channels. J Physiol; 587: 2127-39.

Hill ME, Creed GA, McMullan TF, Tyers A G, Hilton-Jones D, Robinson D O (2001). Oculopharyngeal muscular dystrophy: phenotypic and genotypic studies in a UK population. Brain; 124: 522-6.

Kaminski HJ, al-Hakim M, Leigh RJ, Katirji MB, Ruff RL (1992). Extraocular muscles are spared in advanced Duchenne dystrophy. Ann Neurol; 32: 586-8.

Khurana TS, Prendergast RA, Alameddine HS, Tomé FM, Fardeau M, Arahata K (1995). Absence of extraocular muscle pathology in Duchenne's muscular dystrophy: role for calcium homeostasis in extraocular muscle sparing. J Exp Med; 182: 467-75.

Krasnianski M, Eger K, Neudecker S, Jakubiczka S, Zierz S (2003). Atypical phenotypes in patients with facioscapulohumeral muscular dystrophy 4q35 deletion. Arch Neurol; 60: 1421-5.

Kuwabara T, Lessell S (1976). Electron microscopic study of extraocular muscles in myotonic dystrophy. Am J Ophthalmol; 82: 303-9.

Lee JH, Goto K, Sahashi KO, Nonaka I, Matsuda C, Arahata K (1995). Cloning and mapping of a very short $(10-\mathrm{kb})$ EcoRI fragment associated with facioscapulohumeral muscular dystrophy (FSHD). Muscle Nerve Suppl: S27-31.

Longman C, Brockington M, Torelli S, Jimenez-Mallebrera C, Kennedy C, Khalil N (2003). Mutations in the human LARGE gene cause MDC1D, a novel form of congenital muscular dystrophy with severe mental retardation and abnormal glycosylation of alphadystroglycan. Hum Mol Genet; 12: 2853-61.

Louhichi N, Triki C, Quijano-Roy S, Richard P, Makri S, Méziou M (2004). New FKRP mutations causing congenital muscular dystrophy associated with mental retardation and central nervous system abnormalities. Identification of a founder mutation in Tunisian families. Neurogenetics; 5: 27-34.

Lu H, Luan X, Yuan Y, Dong M, Sun W, Yan C (2008). The clinical and myopathological features of oculopharyngodistal myopathy in a Chinese family. Neuropathology; 28: 599-603.

Lui F, Fonda S, Merlini L, Corazza R (2001). Saccadic eye movements are impaired in Duchenne muscular dystrophy. Doc Ophthalmol; 103: 219-28.

Mendell JR, Rodino-Klapac LR, Rosales XQ, Coley BD, Galloway G, Lewis $S$ (2010). Sustained alpha-sarcoglycan gene expression after gene transfer in limb-girdle muscular dystrophy, type 2D. Ann Neurol; 68: 629-38.

Mercuri E, Muntoni F (2013). Muscular dystrophies. Lancet; 381: 84560.

Miller LA, Romitti PA, Cunniff C (2006). The muscular Dystrophy Surveillance Tracking and Research Network (MD STARnet): surveillance methodology. Birth Defects Res A Clin Mol Teratol; 76: 793-7.

Miller NR (1985). The muscular dystrophies. Walsh \& Hoyt's Clinical Neuro-Ophthalmology, Walsh FB, Hoyt W, ed. Baltimore: Williams and Wilkins;: 794-811.

Minami N, Ikezoe K, Kuroda H, Nakabayashi H, Satoyoshi E, Nonaka I (2001). Oculopharyngodistal myopathy is genetically heterogeneous and most cases are distinct from oculopharyngeal muscular dystrophy. Neuromuscul Disord; 11: 699-702.

Minetti C, Sotgia F, Bruno C, Scartezzini P, Broda P, Bado M (1998). Mutations in the caveolin-3 gene cause autosomal dominant limbgirdle muscular dystrophy. Nat Genet; 18: 365-8.

Muntoni F, Voit T (2004). The congenital muscular dystrophies in 2004: a century of exciting progress. Neuromuscul Disord; 14:635-49.

Norwood FL, Harling C, Chinnery PF, Eagle M, Bushby K, Straub V (2009). Prevalence of genetic muscle disease in Northern England: in-depth analysis of a muscle clinic population. Brain; 132: 3175-86.

Oohira A, Goto K, Ozawa T (1983). Vertical and oblique saccadic eye movements. Jpn J Ophthalmol; 27: 631-46.

Padberg GW, Frants RR, Brouwer OF, Wijmenga C, Bakker E, Sandkuijl LA (1995). Facioscapulohumeral muscular dystrophy in the Dutch population. Muscle Nerve Suppl: S81-4.
Padberg GW, Lunt PW, Koch M, Fardeau M (1991). Diagnostic criteria for facioscapulohumeral muscular dystrophy. Neuromuscul Disord; 1: 231-4.

Pauleikhoff D, Bornfeld N, Bird AC, Wessing A (1992). Severe visual loss associated with retinal telangiectasis and facioscapulohumeral muscular dystrophy. Graefes Arch Clin Exp Ophthalmol; 230: 362-5.

Pedrosa-Domellof $F$, Holmgren Y, Lucas CA, Hoh JF, Thornell LE (2000). Human extraocular muscles: unique pattern of myosin heavy chain expression during myotube formation. Invest Ophthalmol Vis Sci; 41: 1608-16.

Pihko H, Lappi M, Raitta C, Sainio K, Valanne L, Somer H (1995). Ocular findings in muscle-eye-brain (MEB) disease: a follow-up study. Brain \& development; 17: 57-61.

Pitceathly RD, Tomlinson SE, Hargreaves I, Bhardwaj N, Holton JL, Morrow JM (2013). Distal myopathy with cachexia: an unrecognised phenotype caused by dominantly-inherited mitochondrial polymerase gamma mutations. J Neurol Neurosurg Psychiatry; 84: 107-10.

Porter JD, Baker RS (1996). Muscles of a different 'color': the unusual properties of the extraocular muscles may predispose or protect them in neurogenic and myogenic disease. Neurology; 46: 30-7.

Porter JD, Rafael JA, Ragusa RJ, Brueckner JK, Trickett JI, Davies KE (1998). The sparing of extraocular muscle in dystrophinopathy is lost in mice lacking utrophin and dystrophin. J Cell Sci; 111: 180111.

Raducu M, Baets J, Fano O, Van Coster R, Cruces J (2012). Promoter alteration causes transcriptional repression of the POMGNT1 gene in limb-girdle muscular dystrophy type 2O. Eur J Hum Genet; 20: 945-52.

Raitta C, Karli P (1982). Ocular findings in myotonic dystrophy. Ann Ophthalmol; 14: 647-50.

Rodrigue D, Molgat YM (1997). Surgical correction of blepharoptosis in oculopharyngeal muscular dystrophy. Neuromuscul Disord; 7 Suppl 1: S82-4.

Ruegg S, Lehky Hagen M, Hohl U, Kappos L, Fuhr P, Plasilov M (2005). Oculopharyngeal muscular dystrophy - an under-diagnosed disorder? Swiss Med Wkly; 135: 574-86.

Sabharwal R, Cicha MZ, Sinisterra RD, De Sousa FB, Santos RA, Chapleau MW (2014). Chronic oral administration of Ang-(1-7) improves skeletal muscle, autonomic and locomotor phenotypes in muscular dystrophy. Clin Sci (Lond); 127: 101-9.

Salvesen R, Brautaset NJ (1996). Oculopharyngeal muscular dystrophy in Norway. Survey of a large Norwegian family. Acta Neurol Scand; 93: 281-5.

Sansone V, Boynton J, Palenski C (1997). Use of gold weights to correct lagophthalmos in neuromuscular disease. Neurology; 48: 1500-3.

Santavuori P, Somer H, Sainio K, Rapola J, Kruus S, Nikitin T (1989). Muscle-eye-brain disease (MEB). Brain \& development; 11: 147-53.

Scelsa SN, Simpson DM, Reichler BD, Dai M (1996). Extraocular muscle involvement in Becker muscular dystrophy. Neurology; 46: 564-6.

Shimizu Y, Suzuki S, Mori-Yoshimura M, Nagasao T, Toriumi M, Oji T (2013). Surgical treatment of severe blepharoptosis and facial palsy caused by oculopharyngodistal myopathy. J Plast Reconstr Aesthet Surg; 66: e277-80.

Small RG (1968). Coats' disease and muscular dystrophy. Trans Am Acad Ophthalmol Otolaryngol; 72: 225-31.

Smits BW, van der Sluijs BM, van Engelen BG (2011). Neurological picture. The astrologist's posture: a useful clinical observation. J Neurol Neurosurg Psychiatry; 82(2): 164.

Sparks S, Quijano-Roy S, Harper A (1993). Congenital Muscular Dystrophy Overview. In: Pagon RA, Adam MP, Ardinger HH, et al., eds. GeneReviews(R). Seattle (WA).

Statland JM, Sacconi S, Farmakidis C, Donlin-Smith CM, Chung M, Tawil R (2013). Coats syndrome in facioscapulohumeral dystrophy type 1: frequency and D4Z4 contraction size. Neurology; 80: 124750 .

Taylor EW (1915). Progressive vagus-glossopharyngeal paralysis with ptosis: contribution to group of family disease. J Nerv Ment Disord; 42: $129-39$. 
Tomé FM (1994). Oculopharyngeal muscular dystrophy. In: Engel AG F-AC, ed. Myology. New York: McGraw-Hill;: 1233-45.

Udd B (2009). Genetics and pathogenesis of distal muscular dystrophies. Adv Exp Med Biol; 652: 23-38.

Urtasun M, Saenz A, Roudaut C,Poza JJ, Urtizberea JA, Cobo AM (1998). Limb-girdle muscular dystrophy in Guipuzcoa (Basque Country, Spain). Brain; 121: 1735-47.

Uyama E, Uchino M, Chateau D, Tome FM (1998). Autosomal recessive oculopharyngodistal myopathy in light of distal myopathy with rimmed vacuoles and oculopharyngeal muscular dystrophy. Neuromuscul Disord; 8: 119-25.

van der Kooi AJ, Barth PG, Busch HF (1996). The clinical spectrum of limb girdle muscular dystrophy. A survey in The Netherlands. Brain; 119: $1471-80$.

van der Sluijs BM, ter Laak HJ, Scheffer $H$, van der Maarel SM, van Engelen BG (2004). Autosomal recessive oculopharyngodistal myopathy: a distinct phenotypical, histological, and genetic entity. J Neurol Neurosurg Psychiatry; 75: 1499-501.
Vaz-Pereira S, Dansingani K, Holder GE, Webster AR (2014). Macular dystrophy presenting in one of two siblings with limb-girdle muscular dystrophy type 2L due to mutation of ANO5. Eye (Lond); 28: 102-4.

Victor M, Hayes R, Adams RD (1962). Oculopharyngeal muscular dystrophy. A familial disease of late life characterized by dysphagia and progressive ptosis of the evelids. N Engl J Med; 267: 1267-72.

Walker AE (1942). Lissencephaly. Arch Neurol Psychol; 48: 13-29.

Wirtschafter JD, Ferrington DA, McLoon LK (2004). Continuous remodeling of adult extraocular muscles as an explanation for selective craniofacial vulnerability in oculopharyngeal muscular dystrophy. J Neuroophthalmol; 24: 62-7.

Yoshioka M, Kuroki S, Nigami H, Kawai T, Nakamura H (1992). Clinical variation within sibships in Fukuyama-type congenital muscular dystrophy. Brain \& development; 14: 334-7. 